\title{
PHARMACOLOGICAL METHODS IN THE PHONOCARDIOGRAPHIC DIAGNOSIS OF REGURGITANT MURMURS
}

\author{
BY \\ JIŘ́ ENDRYS AND ADELA BÁRTOVÁ
}

From the Cardio-Surgical Centre of the KUNZ-University Hospital, Medical Faculty C.U. Hradec Králové and from the Ist Department of Medicine, Palacky's University, Olomouc, Czechoslovakia

Received March 3, 1961

The diagnosis of the source of regurgitant murmurs is an acute problem of contemporary cardiology in relation to the surgical treatment of valvular heart disease. The distinction between mitral and tricuspid systolic regurgitant murmurs may cause considerable difficulties even after assessment of the entire clinical picture, including detailed hæmodynamic investigation. The inspiratory increase of the systolic murmur caused by tricuspid incompetence (Rivero-Carvallo, 1950) was found by Uricchio et al. (1958) in regurgitation of slight degree only and by Sepulveda and Lukas (1955) in a single patient out of ten. The differential diagnosis between incompetence of the aortic and pulmonary valves is even more difficult, particularly when not accompanied by significant hæmodynamic changes.

We therefore felt the need for devising a system of phonocardiographic differential diagnosis, assisting distinction between regurgitant murmurs from the right and left heart. We used the pharmacological effect of drugs to change hæmodynamics in the pulmonary and systemic circulations producing secondary changes in the murmurs.

\section{METHOD}

Phonocardiographic tracings were registered by direct transcription on an Elema Mingograph 42, by a phonocardiographic device manufactured by the same firm. The electrocardiogram was registered simultaneously with sound recordings in the high frequency band from one or two chest positions. Simultaneously with phonocardiographic recordings, the majority of patients had direct pressure readings from the radial or femoral artery registered by an Elema electromanometer. Patients with auricular fibrillation had their mean systemic artery pressure registered by electric integration. Some patients had their phonocardiographic investigation performed during heart catheterization and pressure changes in the right heart were recorded simultaneously. The effects on the circulation of amylnitrite, nor-epinephrine, serotonin and methoxamine were studied. Amylnitrite was administered by inhalation until a fall of blood pressure or visible reddening of the skin was produced-usually 30-60 seconds later. The other drugs were given intravenously dissolved in $20 \mathrm{ml}$. of normal saline, administration lasting 1 minute. The dosage of nor-epinephrine was 20-40 gamma, of methoxamine 3-5 mg. in 30 seconds, and of serotonin $2 \cdot 0-2 \cdot 5 \mathrm{mg}$. in 60 seconds. The phonocardiogram, electrocardiogram and arterial pulse were registered during held expiration at a paper speed of $50 \mathrm{~mm}$./sec., and occasionally at speeds of $25 \mathrm{~mm}$. or $100 \mathrm{~mm}$./sec. Tracings were recorded immediately before administration of each drug and afterwards at $15 \mathrm{sec}$. intervals from the start of administration for the first 2 minutes. Further tracings were recorded $2 \frac{1}{2}, 3,4$, and 6 minutes from the commencement of drug administration, and sometimes later. During amylnitrite inhalation, tracings were recorded every $10-15$ seconds from the start of inhalation for the 
first 30-60 seconds. Each recording lasted 3-5 seconds including 8-12 cardiac contractions. The majority of patients received all 4 drugs during a single session with 10 minutes between successive administrations. The changes in intensity of the murmur were assessed as follows: more than twofold increase or reduction of murmur amplitude indicated as ++ , or -- , increase or reduction of murmur intensity less than double or half the original amplitude as + or - , and a negative response or equivocal change as 0 .

This communication deals with a series of patients whose clinical findings, or some of the special investigations, provided evidence of valvular incompetence. The evidence for aortic incompetence consisted of a decrescendo diastolic murmur situated over the aortic orifice associated with a wide arterial pulse pressure and left ventricular enlargement. The one patient with pulmonary incompetence had slight pulmonary stenosis, confirmed by heart catheterization, and post-stenotic dilatation of the main pulmonary artery; there was a loud systolic murmur and a loud diastolic decrescendo murmur over the base with propagation down the left sternal margin without evidence of enlargement of the left ventricle, or increased arterial pulse pressure and without increased aortic pulsation on fluoroscopy. The congenital pulmonary incompetence in the second patient was confirmed by the dilution curve from the right ventricle obtained by injection of the dye into the pulmonary artery. Mitral incompetence was confirmed in the majority of patients by operation on the mitral orifice and by dilution curves and angiocardiography both performed during the left heart catheterization. The dye and the contrast material were injected into the left ventricle (Steinhart and Endrys, 1960; Endrys and Steinhart, in press).

Tricuspid incompetence was confirmed either at necropsy, surgery or catheterization and was always associated with mitral stenosis. A total of 64 patients were investigated, some suffering from combined valvular disease.

\section{RESULTS}

The effect of individual drugs on the intensity of regurgitant murmurs is summarized in the table and shows that drugs which increase peripheral resistance and thereby pressure in the systemic circulation (nor-epinephrine and methoxamine) also increase regurgitation at the valves of the left heart (Braunwald, E. et al., 1958; Carlier and Lejeune-Ledant, 1959) whereas serotonin, by increasing pulmonary resistance and pulmonary artery pressure, intensifies right heart regurgitation. Amylnitrite, in dose sufficient to produce a fall in systemic pressure, increases outflow of blood from the left ventricle, thereby reducing left heart regurgitation and diminishing murmurs caused by incompetence of left heart valves. Increase of the systolic murmur following nor-epinephrine in tricuspid incompetence may be explained by the effect of nor-epinephrine on the pulmonary vascular bed. This drug causes pulmonary vasoconstriction, thereby raising the pulmonary artery pressure (Aviado and Schmidt, 1957, Fig. 1B). Increase of the systolic murmur in tricuspid incompetence following amylnitrite (Fig. 1D) can be explained by increased blood flow through the right heart and by a rise of the pulmonary artery pressure caused by increase of the left atrial pressure in cases with mitral stenosis (Endrys, J., et al., in press). The rise of the left atrial pressure may be partly

TABLE I

Pharmacodynamic Effects on Murmur Intensity

\begin{tabular}{l|c|c|c|c|c}
\hline & $\begin{array}{c}\text { Number of } \\
\text { patients }\end{array}$ & Nor-epinephrine & Amylnitrite & Serotonin & Methoxamine \\
\hline Mitral incompetence .. & 32 & + & - & 0 & + \\
Tricuspid incompetence & 9 & $+*$ & + & + & 0 \\
Aortic incompetence .. & 21 & + & + & + \\
Pulmonary incompetence & 2 & + & + & 0 \\
\hline
\end{tabular}

Increase of murmur: +

Decrease of murmur: -

No change in intensity: 0

* In one patient no increase of murmur was observed. 


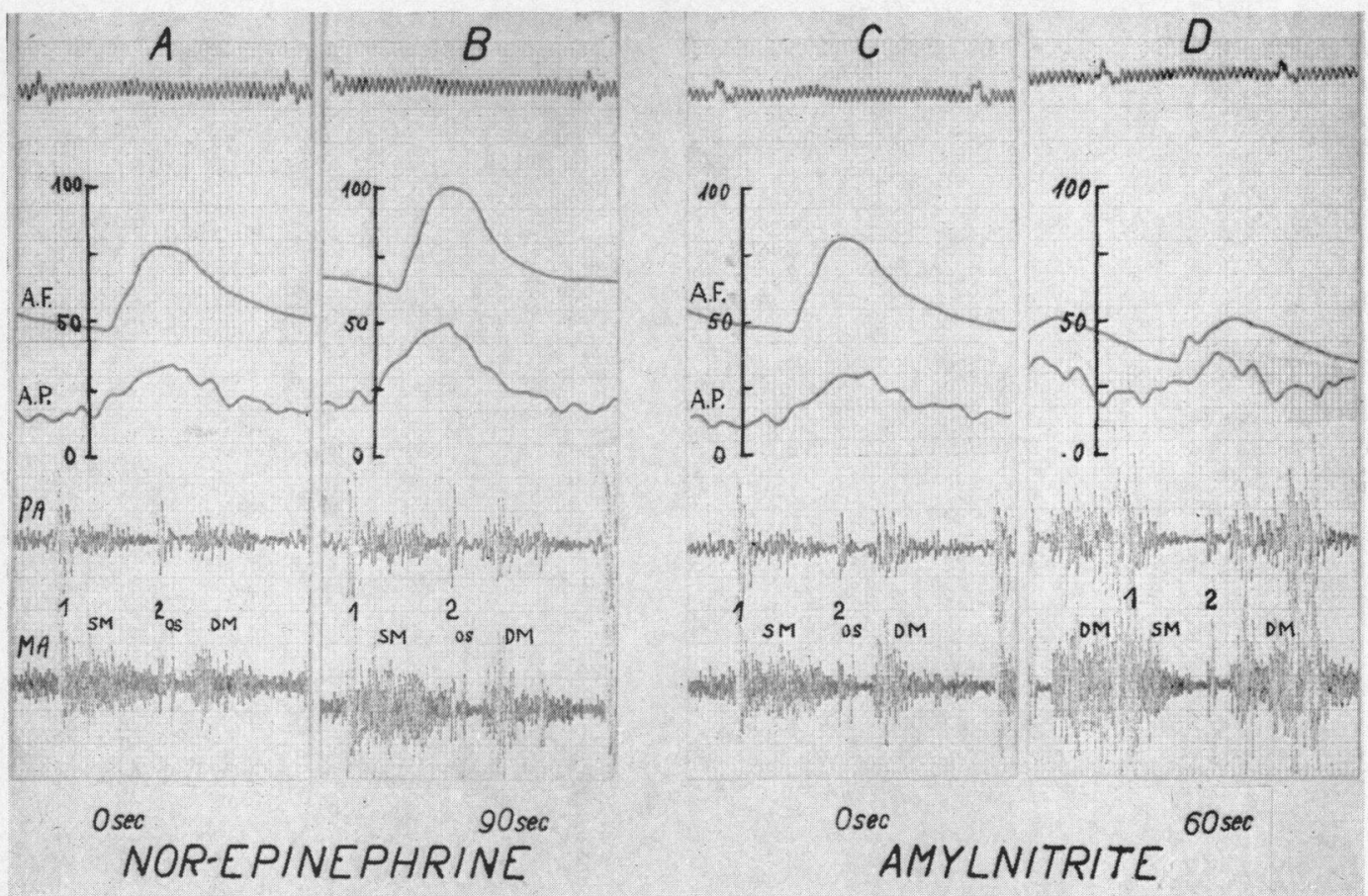

FIG. 1.-Mitral stenosis and regurgitation. Phonocardiogram from apical region (MA) recorded during catheterization simultaneously with blood pressure in pulmonary artery (A.P.) and femoral artery (A.F.). On tracing B, 90 secs. after nor-epinephrine administration, pressure has risen in the femoral and pulmonary arteries simultaneously with an increase in amplitude of the systolic murmur. On tracing $D$, $60 \mathrm{sec}$. after amylnitrite inhalation, simultaneously with a drop in femoral artery pressure, decrease of the systolic murmur and marked increase of the diastolic murmur have taken place. $\mathrm{SM}=$ syst. murmur, $\mathrm{DM}=$ diast. murmur, $1=$ first sound, $2=$ second sound, $O S=$ opening snap. Tracing of pulmonary artery pressure was superimposed artificially on other tracings.

due to increased minute volume, and in part to the tachycardia induced by amylnitrite, which shortens diastole and reduces the time during which the increased minute volume can flow through the narrowed mitral orifice.

\section{Discussion}

There is a scarcity of papers dealing with the effects of drugs on murmurs, though some reports appeared as early as 1932 when Kahler noticed that amylnitrite reduced the apical systolic murmur of mitral incompetence and used this for differentiation from "innocent" murmurs. Our experience confirms his conclusions. Barlow and Shillingford (1958) employed amylnitrite to differentiate the systolic murmur of mitral incompetence from that of aortic stenosis. Only recently Vogelpoel et al. (1959) reported the use of amylnitrite for detecting the source of systolic murmurs. They found that the systolic murmur of mitral incompetence decreased after amylnitrite while that of tricuspid incompetence increased. Our results are in agreement with these statements.

Soloff et al. (1958) studied alterations in murmurs following nor-epinephrine and found an increase of the apical systolic murmur in mitral incompetence but did not observe an increase of the diastolic murmur in aortic incompetence. In our patients with aortic incompetence the diastolic regurgitant murmur always increased in intensity following nor-epinephrine administration (Fig. $2 \mathrm{AB})$. Thus the raised peripheral vascular resistance from nor-epinephrine leads to increased regurgitation of the incompetent aortic or mitral valves. 


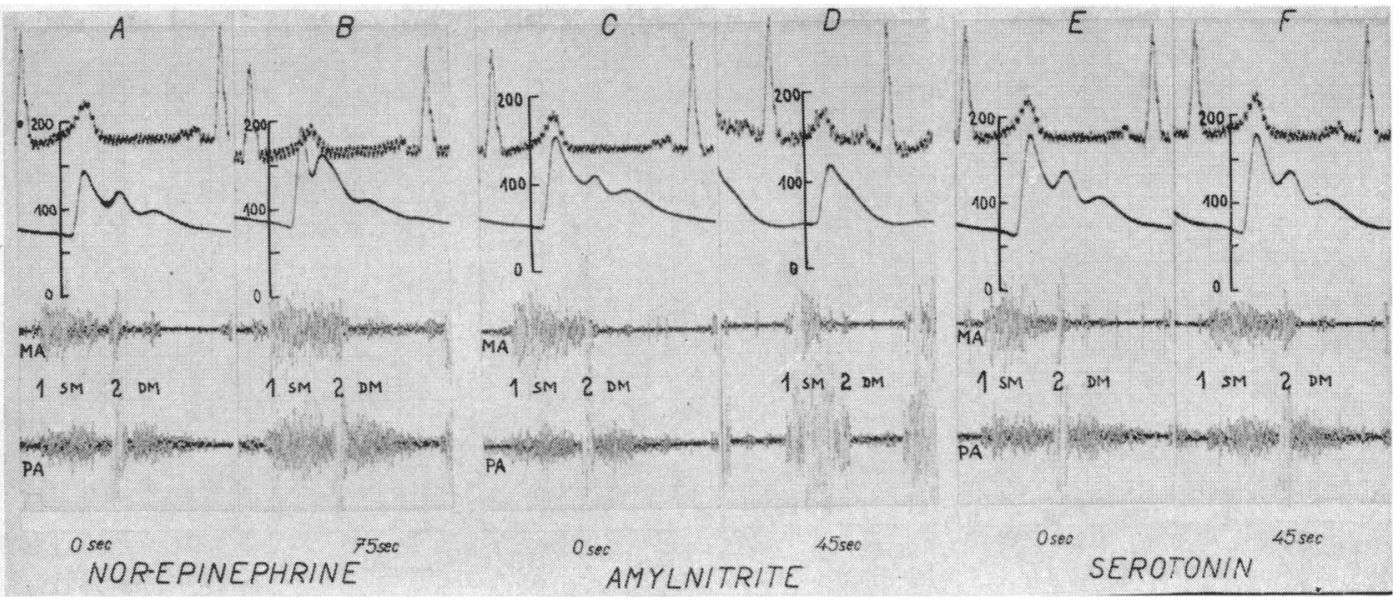

FIG. 2.- Mitral and aortic insufficiency with phonocardiograms from mitral area and pulmonary area (PA). Increase of systolic apical murmur following nor-epinephrine (B), decrease after amylnitrite (D) and no change after serotonin (F) are in favour of mitral incompetence. Identical changes in the diastolic murmur at the base are in favour of the source of the regurgitant murmur being on the left side of the heart, i.e. aortic incompetence. Increase of systolic murmur at the base after nor-epinephrine may be explained by increase of ejection volume induced by increased aortic regurgitation and hæmodynamically insignificant aortic stenosis.

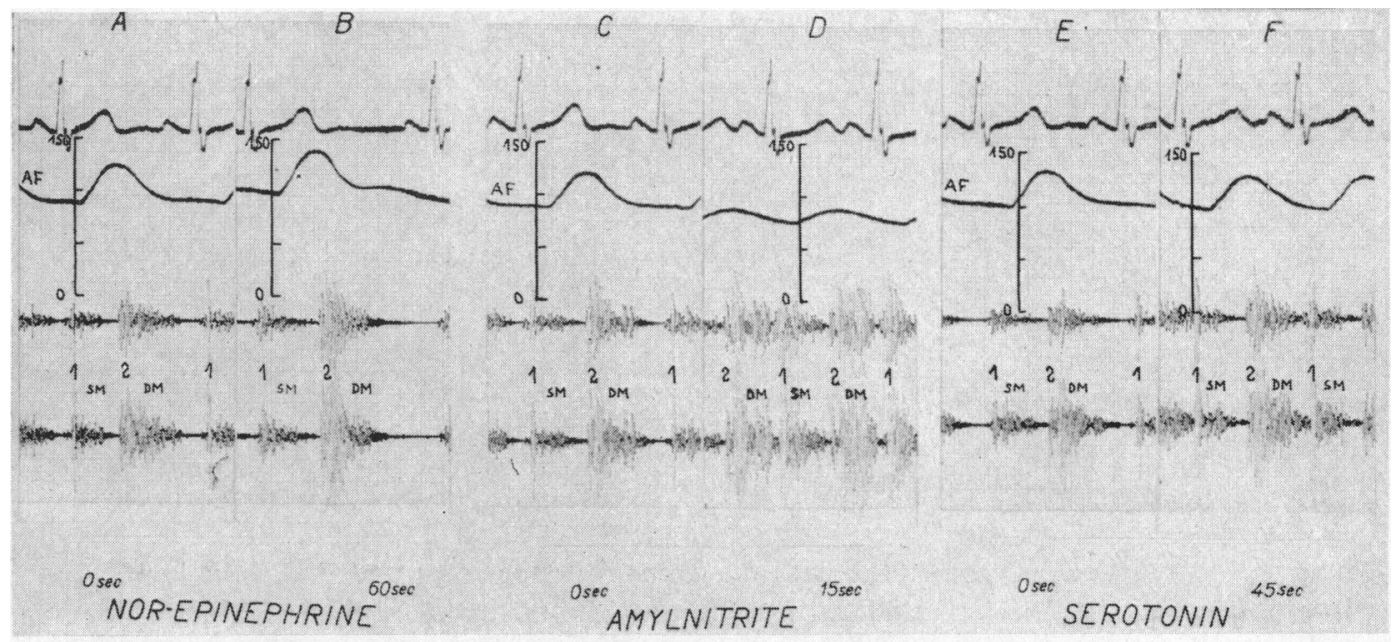

FIG. 3.-Pulmonary stenosis and regurgitation with phonocardiograms from mesocardium. Following serotonin (tracing F) visible increase of the diastolic regurgitant murmur has taken place even though pressure in the femoral artery remained unchanged, and the diastolic murmur increased after amylnitrite despite the significant drop in femoral artery pressure. These findings exclude aortic regurgitation and favour pulmonary regurgitation.

Nor-epinephrine also increased the systolic murmur of tricuspid incomptence in eight of our@्? nine patients (Fig. 4AB) by increasing pulmonary vascular resistance (Aviado \& Schmidt, 1957, Fig. 1). Thus nor-epinephrine alone cannot be used for distinguishing between mitral and tricuspido incompetence. In order to come to a reliable decision as to whether the regurgitant murmur is situated in the right or left heart, we need to use a drug which affects either the pulmonary circulation $\underset{\otimes}{\circ}$ alone or the systemic circulation alone. It appears that methoxamine has this property (Aviado and 


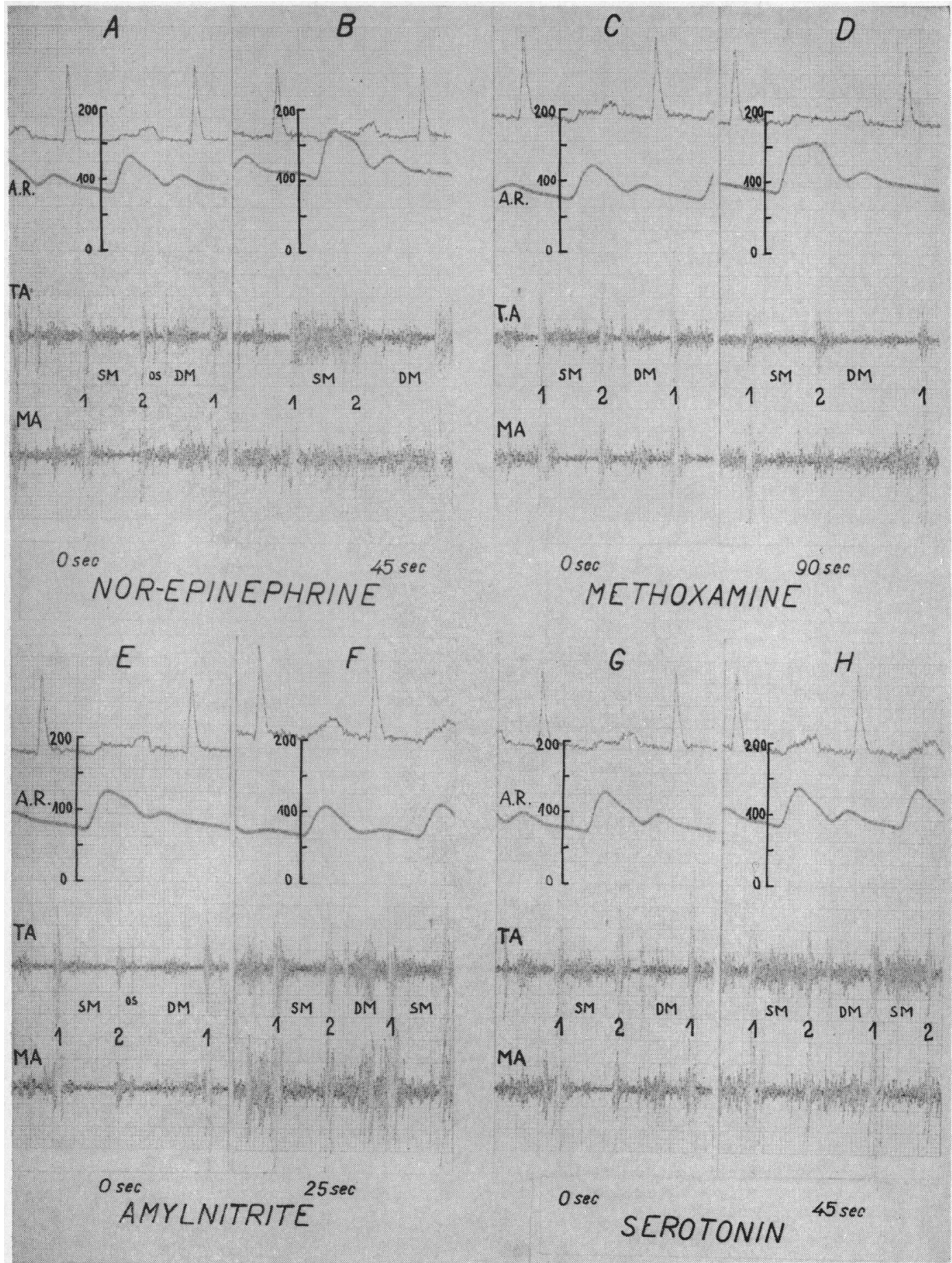

Fig. 4.-Tight mitral stenosis and combined tricuspid valve disease with phonocardiograms from apical region (MA) and lower sternum (TA) recorded simultaneously with radial artery pressure. On tracings B, F, H, i.e. following administration of nor-epinephrine, amylnitrite and serotonin, increase of the regurgitant murmur due to tricuspid incompetence has occurred, whereas methoxamine failed to induce intensification of the murmur despite the rise of radial artery pressure. 


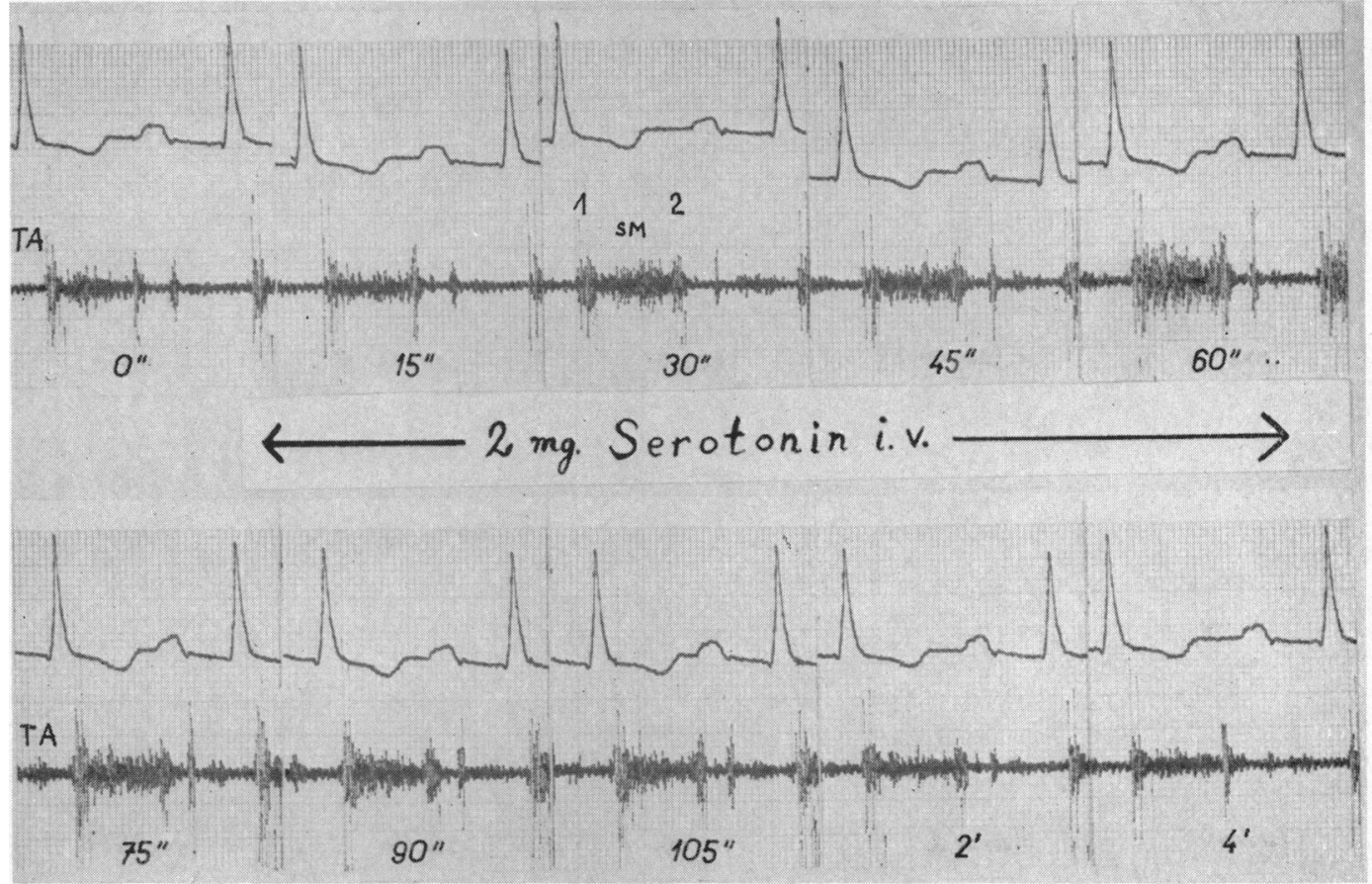

FIG. 5.-Phonocardiogram from lower sternum of same patient as in Fig. 4. Administration of serotonin induced marked increase of the systolic murmur, the maximum was reached $60 \mathrm{sec}$. after starting injection of serotonin. After 2 and 4 minutes the murmur diminished and regained its original intensity.

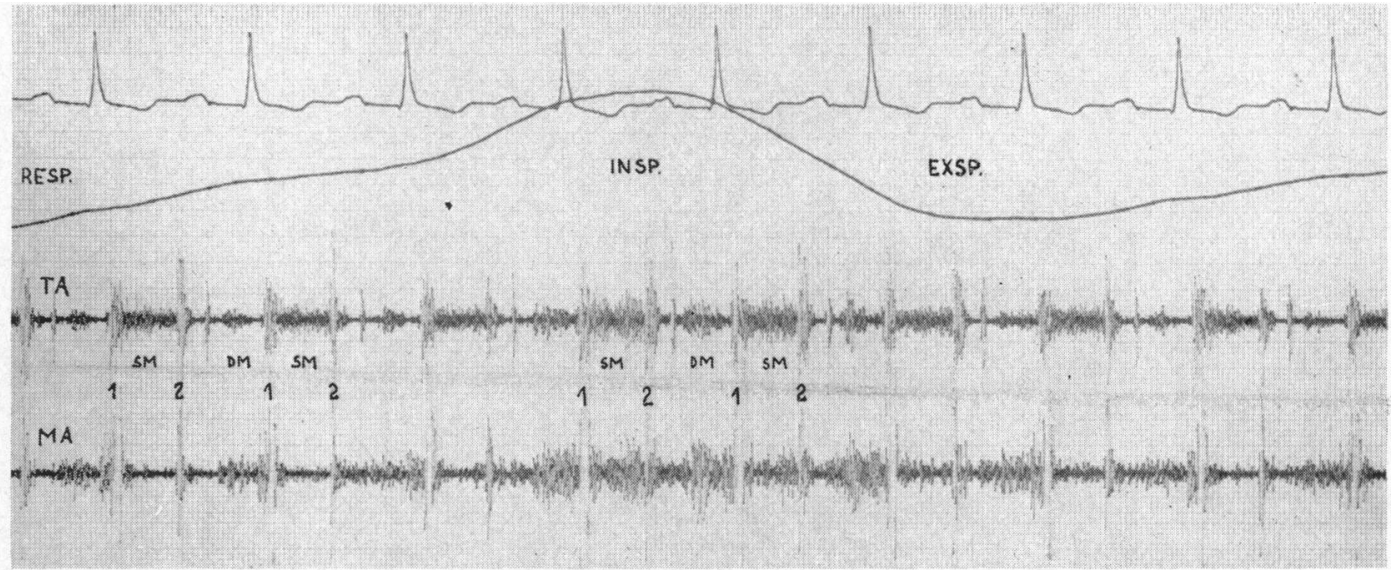

FIG. 6.-Phonocardiogram from apical region (MA) and lower sternum (TA) of same patient as in Fig. 4 and 5. The tracing shows dependence of systolic and diastolic murmur increase on inspiration. Findings point to tricuspid valvular disease.

Schmidt, 1957) since it is without vasoconstriction effect on the pulmonary vascular bed, but exerts marked vasoconstrictive action on the systemic circulation. Serotonin has the opposite effect (Page, 1959). Our preliminary results are in agreement with these assumptions, but further detailed studies on the hæmodynamic effects of these drugs are required. We found it important to 
record the arterial pressure simultaneously with changes in the murmur immediately after the administration of the drugs, particularly during the initial periods of change, before compensatory adjustment of minute volume has developed. This applies particularly to patients with signs of failure who respond only with slight fluctuations of pressure. It is, therefore, necessary to register :hese changes during their initial phase of maximal fluctuation. Observations on Fig. $4 \mathrm{GH}$ may be ased to illustrate this point. Increase of the systolic murmur over the lower sternum following administration of serotonin without simultaneous change of systemic pressure is in favour of tricuspid ncompetence. Failure of the systolic murmur of mitral incompetence to change in intensity ollowing amylnitrite does not disprove mitral regurgitation, however, unless there has been a simultaneous fall in systemic artery pressure.

In conclusion, it is our impression that these pharmacological methods of altering hæmodynamics are superior to respiratory changes in differentiating mitral from tricuspid regurgitant murmurs, but a definite decision must await a larger series of observations.

As no published report could be found dealing with the employment of serotonin and methoxamine for influencing murmurs, and making use of alterations in their intensity for tracing "heir source, we have taken the liberty of presenting our results in a small number of patients. It seems that the method of influencing murmurs pharmacologically will provide another weapon ikely to improve not only our accuracy in diagnosis of valvular heart disease, but also leading io better understanding of its patho-physiology.

\section{SUMMARY}

We have described the use of a pharmacological technique in 64 patients employing nor-epinephrine, amylnitrite, serotonin and methoxamine to change the intensity of regurgitant murmurs.

It was found that nor-epinephrine and methoxamine by raising pressure in the systemic circulation increased murmurs caused by incompetence of left heart valves. They increase, therefore, mitral \$ystolic and aortic diastolic murmurs.

Serotonin, by raising pulmonary artery pressure, increased regurgitation at the tricuspid and pulmonary valves and thereby also the amplitude of the tricuspid systolic and pulmonary diastolic murmurs.

- Amylnitrite reduced regurgitant murmurs from the left heart and increased regurgitant murmurs rom the right heart, provided these were associated with mitral stenosis.

Since nor-epinephrine increased vascular resistance in both the systemic and pulmonary cirsulations, it could not be used to differentiate right and left sided regurgitant murmurs. Serotonin and methoxamine were found to be suitable for this purpose since these drugs exert an isolated iffect on the pulmonary and systemic circulations respectively.

Amylnitrite, under certain conditions, also served this purpose by increasing regurgitant murmurs of the right and reducing regurgitant murmurs of the left heart.

Serotonin was supplied by E. Merck, Aktiengesellschaft, Darmstadt, and Vasoxyl (brand of methoxamine) by Dr. Bloomfield of Burroughs Wellcome \& Co., Tuckahoe, U.S.A.

\section{REFERENCES}

Aviado, D. M., and Schmidt, C. F. (1957). J. Pharm. exp. Ther., 120, 512.

Barlow, J., and Shillingford, J. (1958). Brit. Heart J:, 20, 162.

Braunwald, E., Welch, G. H., Jr., and Morrow, A. G. (1958). J. clin. Invest., 37, 35.

Carlier, J., and Lejeune-Ledant, G. N. (1959). J. thorac. cardiovasc. Surg., 38, 2.

Kahler, H. (1932). Wien Arch. inn. Med., 23, 349.

Page, I. H. (1959). Physiol. Rev., 38, 277.

Rivero-Carvallo, J. M. (1950). Arch. Inst. Cardiol., Mexico, $20,1$.

Sepulveda, G., and Lukas, P. S. (1955). Circulation, 11, 552.

Soloff, L. A., Wilson, M. F., Winters, W. L. Jr., and Zatuchni, J. (1958). Circulation, 18, 783.

Steinhart, L., and Endrys, J. (1960). Fortschr. Röntgenstr., 93, 753.

'Uricchio, J. F., Bentivoglio, L., Gilman, R., and Likoff, W. (1958). Amer. J. Med., $25,224$.

Vogelpoel, L., Nellen, M., Swanepoel, A., and Schrire, V. (1959). Lancet, 2, 810. 